\title{
Ion Irradiation Studies of Soft Magnetic Metallic Glasses
}

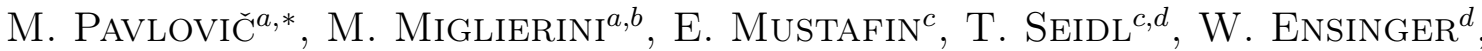 \\ I. STRAŠÍK ${ }^{c, e}$ AND M. ŠOKA ${ }^{a}$ \\ ${ }^{a}$ Slovak University of Technology, Ilkovičova 3, 81219 Bratislava, Slovak Republic

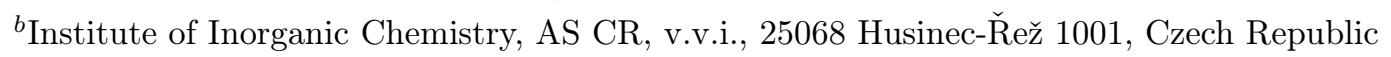 \\ ${ }^{c}$ GSI Helmholtzzentrum für Schwerionenforschung, Planckstr. 1, 64291 Darmstadt, Germany \\ ${ }^{d}$ Darmstadt University of Technology, 64287 Darmstadt, Germany \\ ${ }^{e}$ Johann Wolfgang Goethe Universität Frankfurt am Main \\ Max-von-Laue-Str. 1, 60438 Frankfurt am Main, Germany
}

Finemet and Vitrovac ${ }^{\circledR} 6025$ metallic glasses were irradiated by light $(\mathrm{N})$ and heavy (Au and Ta) ions at different energies from $110 \mathrm{keV}$ to $250 \mathrm{MeV} / \mathrm{u}\left(\mathrm{MeV}\right.$ per mass unit) and fluences from $1 \times 10^{11}$ ions $/ \mathrm{cm}^{2}$ to $1 \times 10^{17}$ ions $/ \mathrm{cm}^{2}$. They were analysed by the Mössbauer spectrometry and magnetic susceptibility measurements. Qualitative differences were observed between the radiation effects caused by light and heavy ions.

PACS numbers: 76.80.+y, 75.30.Cr, 75.50.-y, 61.80.-x

\section{Introduction}

Some metallic glasses are considered as candidates for magnetic cores of accelerator radio-frequency $(\mathrm{RF})$ -cavities. In this particular application, they are exposed to ion radiation that may alter their magnetic properties [1]. The spectrum of particle species, energies and fluences is rather broad because the irradiating ions origin from complex interaction of lost primary heavy ions with the beam-pipe wall. That is why a systematic study of the influence of ion bombardment on magnetic properties of the materials used for the magnetic cores of the $\mathrm{RF}$-cavities is necessary.

\section{Materials and methods}

This paper deals with Finemet and Vitrovac $\circledast 6025$. These materials are considered for the facility for antiproton and ion research (FAIR) RF-cavities [2]. Finemet $\left(\mathrm{Fe}_{74} \mathrm{Cu}_{1} \mathrm{Nb}_{3} \mathrm{Si}_{16} \mathrm{~B}_{6}\right)$ was irradiated by $110 \mathrm{keV} \mathrm{N}$ and $593 \mathrm{MeV} \mathrm{Au}$ ions. In case of $\mathrm{N}$ ions, the fluences up to $1 \times 10^{17} \mathrm{ions} / \mathrm{cm}^{2}$ were applied. The mean projected range was $133 \mathrm{~nm} \pm 47 \mathrm{~nm}$ (straggling). In case of $\mathrm{Au}$ ions, the fluences up to $1 \times 10^{13}$ ions $/ \mathrm{cm}^{2}$ were applied. The mean projected range was $18.9 \mu \mathrm{m} \pm 575 \mathrm{~nm}$. The influence of ion bombardment on surface and bulk regions of the samples was analysed by conversion electron Mössbauer spectrometry (CEMS) and transmission Mössbauer spectrometry (TMS), respectively.

Vitrovac ${ }^{\circledR} 6025\left(\mathrm{Co}_{67} \mathrm{Fe}_{4} \mathrm{Mo}_{2} \mathrm{Si}_{16} \mathrm{~B}_{11}\right.$, [3]) was irradiated by $\mathrm{Au}$ ions at $11.1 \mathrm{MeV} / \mathrm{u}$ and $\mathrm{Ta}$ ions at $11.1 \mathrm{MeV} / \mathrm{u}$ and $250 \mathrm{MeV} / \mathrm{u}$. At these energies, the range is longer than the sample thickness (about $23 \mu \mathrm{m}$ ). Irradiations with fluences up to $1.2 \times 10^{13} \mathrm{ions} / \mathrm{cm}^{2}$ were performed. The samples were analysed by magnetic susceptibility measurements [4].

\footnotetext{
* corresponding author; e-mail: marius.pavlovic@stuba.sk
}

Irradiation experiments were accompanied by SRIM2010 simulations (stopping and ranges of ions in matter, SRIM). The depth-profiles of ionization and vacancy-concentration were simulated. The vacancy-concentration was converted to dpa (displacement per atom) that depends on the fluence. The fluences were chosen according to actual results of the sample analysis.

\section{Results and discussion}

Samples of Finemet irradiated by $110 \mathrm{keV} \mathrm{N}$ ions showed changes in spectral parameters, especially in isomer shift, at $2 \times 10^{16}$ ions $/ \mathrm{cm}^{2}$ [5]. This is the fluence that causes radiation damage of dpa $>10$ due to elastic nuclear stopping. The electronic stopping is on the level of $0.6 \mathrm{MeV} / \mu \mathrm{m}$. Its depth-profile is nearly uniform within the depth accessible by CEMS $(\approx 200 \mathrm{~nm})[6]$.

TMS of the samples irradiated with $593 \mathrm{MeV}$ Au ions exhibited changes in orientation of the net magnetic moment at $1 \times 10^{12}$ ions $/ \mathrm{cm}^{2}$ [5], which is a fluence causing the radiation damage due to nuclear stopping of less than 0.01 dpa (Fig. 1). Moreover, the damaged region is restricted mainly to the range-region of irradiating ions and can hardly influence significantly the MS-spectra in transmission geometry that provides information from the sample bulk. It is the electronic stopping that reaches considerably higher values of about $47 \mathrm{MeV} / \mu \mathrm{m}$ in comparison with nitrogen and that influences a larger sample volume (its depth-profile is broader compared with the nuclear stopping one). All these arguments indicate that whereas the damage by light ions is dominated by nuclear stopping and can be correlated to dpa, the damage by heavy ions is governed by electronic stopping and cannot be correlated to dpa. As a consequence, heavy ions are more effective in damaging the materials because of higher proton number, $Z$, which increases the electronic stopping by $Z^{2}$ at the same projectile velocity. Therefore changes of magnetic properties must be expected at lower fluences compared with light ions. 


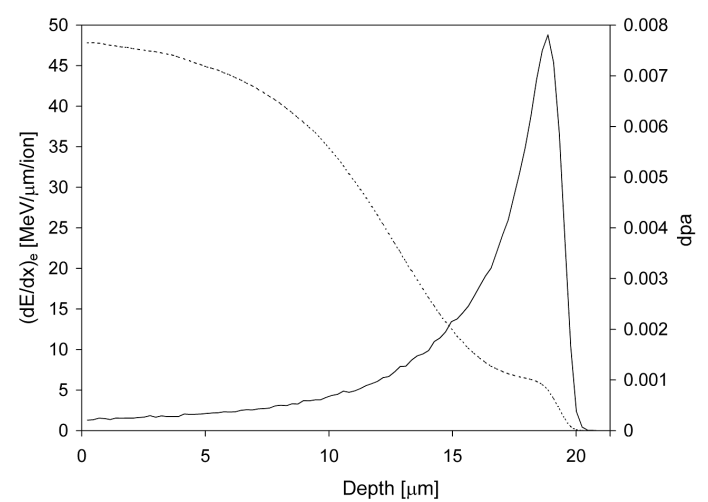

Fig. 1. Electronic stopping (dotted line) and dpa (solid line) in Finemet irradiated by $593 \mathrm{MeV} \mathrm{Au}$ ions, $1 \times 10^{12}$ ions $/ \mathrm{cm}^{2}$.

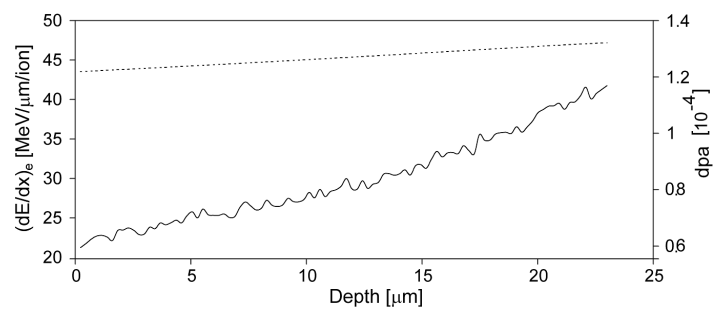

Fig. 2. Electronic stopping (dotted line) and dpa (solid line) in Vitrovac ${ }^{\circledR}$ irradiated by $11.1 \mathrm{MeV} / \mathrm{u}$ Ta ions, $1 \times 10^{12}$ ions $/ \mathrm{cm}^{2}$.

Based on the results obtained for Finemet, irradiations of Vitrovac ${ }^{\circledR} 6025$ concentrated on heavy ions. The energy of $11.1 \mathrm{MeV} / \mathrm{u}$ was used to ensure high electronic stopping with a uniform depth-profile (Fig. 2). An extra experiment was done at $250 \mathrm{MeV} / \mathrm{u}$ representing low electronic stopping of about $9.75 \mathrm{MeV} / \mu \mathrm{m}$. Magnetic susceptibility was measured before and after irradiation and its relative change is plotted as a function of the fluence in Fig. 3 for $11.1 \mathrm{MeV} / \mathrm{u}$. Samples irradiated by $250 \mathrm{MeV} / \mathrm{u}$ showed no remarkable changes of magnetic susceptibility because of lower electronic stopping compared with the 11.1 MeV/u. A deeper discussion on physical aspects of

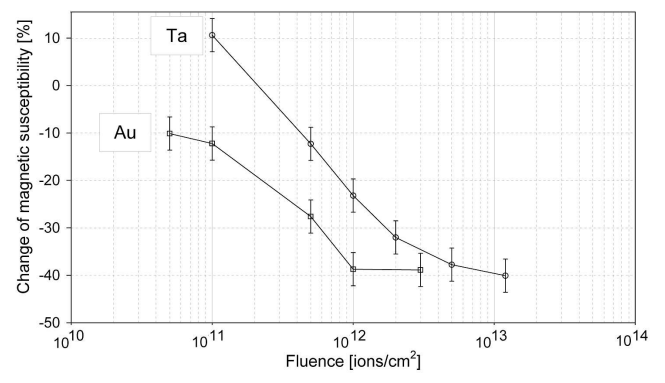

Fig. 3. Relative change of magnetic susceptibility of Vitrovac ${ }^{\circledR}$ after irradiation by $\mathrm{Ta}$ (circles) and $\mathrm{Au}$ (squares) ions as a function of fluence, $11.1 \mathrm{MeV} / \mathrm{u}$. radiation damage caused by light and heavy ions can be found in Ref. [7].

Although the materials were studied by two different techniques, the results are reasonably consistent, as both materials started showing degradation changes at fluences crossing $1 \times 10^{11}$ ions $/ \mathrm{cm}^{2}$. Application of other complementary techniques is currently in progress as well as MS and susceptibility measurements of the same material (Vitroperm).

\section{Conclusions}

Radiation damage of materials caused by ion irradiation is intensively studied and it is observed that there are qualitative differences in damage mechanisms between light and heavy ions [7]. This finding was confirmed also by our experiments for ions irradiating the soft magnetic metallic glasses at very high energies up to $250 \mathrm{MeV} / \mathrm{u}$. An attempt to find quantitative criteria was done as well. Whereas the radiation damage by light ions can be correlated to dpa and occurs at dpa $>10$ for materials under investigation, radiation damage by heavy ions is related to high ionisation density (about $47 \mathrm{MeV} / \mu \mathrm{m}$ ) and occurs even at very small dpa values (less than $1.2 \times 10^{-4}$ ). In terms of fluence, the Mössbauer isomer shift changed at $2 \times 10^{16}$ ions $/ \mathrm{cm}^{2}$ for $110 \mathrm{keV} \mathrm{N}$, whereas the fluence of $1 \times 10^{12}$ ions $/ \mathrm{cm}^{2}$ led to reorientation of the net magnetization in case of $593 \mathrm{MeV} \mathrm{Au}$ (both in Finemet).

Irradiation of Vitrovac ${ }^{\circledR} 6025$ showed that magnetic susceptibility changed at fluence as low as $1 \times 10^{11}$ ions $/ \mathrm{cm}^{2}$ at energies about $11 \mathrm{MeV} / \mathrm{u}$, but no change was observed at $250 \mathrm{MeV} / \mathrm{u}$. An enhancement of susceptibility was observed at low fluences (for Ta but not for $\mathrm{Au}$ ) and a saturation tendency appeared at fluencies over $1 \times 10^{12}$ ions $/ \mathrm{cm}^{2}$ (for both ion species). The saturation level was about $-40 \%$ of the non-irradiated samples. The saturation tendency may be caused by overlapping of individual ion tracks.

\section{Acknowledgments}

This work was supported by VEGA 1/0033/10, KAN 400100653, VEGA 1/0129/09, BMBF 06DA90251 and GSI Darmstadt.

\section{References}

[1] R. Dubey, A. Gupta, P. Sharma, N. Darowski, G. Schumacher, J. Magn. Magn. Mater. 310, 2491 (2007).

[2] P. Spiller, K. Blasche, B. Franczak, M. Kirk, P. Huelsmann, C. Omet, S. Ratschow, J. Stadlmann, Nucl. Instrum. Methods Phys. Res. A 544, 117 (2005).

[3] S. Flohrer, G. Herzer, J. Magn. Magn. Mater. 322, 1511 (2010).

[4] V. Jančárik, E. Ušák, J. Electr. Eng. 50, 63 (1999).

[5] M. Miglierini, A. Lančok, M. Pavlovič, Hyperfine Interact. 189, 45 (2009).

[6] M. Miglierini, A. Lančok, M. Pavlovič, Phys. Met. Metallogr. 109, 469 (2010).

[7] A. Rivera, J. Olivares, G. García, J.M. Cabrera, F. Agulló-Rueda, F. Agulló-López, Phys. Status Solidi A 206, 1109 (2009). 